\title{
Social Commerce's Operation Activities Patterns in Thailand
}

\author{
Raywadee Sakdulyatham \\ Rajapruk University \\ rasakd@rpu.ac.th \\ Somjaree Preeyanont \\ Chulalongkorn University \\ somjaree@cbs.chula.ac.th
}

\begin{abstract}
Nowadays, S-Commerce is a popular business operation channel and tends to welcome more new business operators. However, most of them have an obstacle in choosing the correct tools for operations which are available in many patterns. The main objective of this research is to find the most popular pattern of trading activities through S-Commerce in Thailand as to be guidelines for new business operators. A survey by interview was conducted on methods used to implement buying and selling activities according to consumer buying decision-making process from 120 S-Commerce business operators in the Bangkok Metropolitan Region by convenience sampling. The obtained methods were analyzed to find out the most common patterns. The findings from the study showed that most sellers selected Facebook to promote their businesses by providing details through Facebook pages and allowing customers to contact them for more information via inbox and telephone. Making purchases, informing payment channels, and confirming product delivery are done in inbox and customers give feedback on Facebook pages, followed by using Facebook in combination with LINE. Details of the product were given through Facebook pages and LINE Timeline. Customers contact for more information through LINE Chat and telephone. Making purchases and informing payment channels are done through LINE Chat. Products are sent directly to customers. Customers give feedback through Facebook pages. Some buyers and sellers were asked and it was found that most buyers would like to ask for additional details through other channels and sellers would like to expand their groups of customers. Therefore, it is necessary to increase channels in implementing activities that are making purchase order and inventory management difficult. In this regard, they selected to offer products through different channels but control the number or ordering channels to be limited to ensure purchase orders will be better managed, suitable for small business with small capital. Additional functions should be developed in bringing purchase orders from chat channel to store and manage in a systematic manner and be easy to use. It can be seen that S-Commerce has been conducted worldwide and its
\end{abstract}


tendency seems to be moving higher. Some products of Thailand are desired by foreigners. In order to expand customer bases overseas, an automatic language translation functions on social media should be developed.

Keywords: Social Commerce (S-Commerce); Business operation; Buying and selling activities; Activities pattern

\section{INTRODUCTION}

Currently, many countries across the world have developed their economic and social systems by using digital technology as a tool to support their operations and apply in everyday life, causing changes in structures and patterns of economic activities including production process, trading, service and other social processes. In this regard, Thailand needs to accelerate digital technology as a tool to mobilize country development. Emphasis is placed on elevating quality of life and access to public services of people thoroughly and equitably including building business operators and digital businesses [1].

Especially electronic commerce, a world popular business transaction in which information technology is used in the process of trading and product exchange. It can increase business efficiency from searching for products, details and properties of products, and product prices for enhancing buying decision making when online shopping can be done conveniently at any time [2]. It is a business operation pattern consistent with a policy on digital development plan for Thailand economy and society. It is expected that electronic commercial transactions shall have an increase in market share to $8.2 \%$ and market value more than 470,000 million baht within 2022 [3]. As of today, electronic commerce has been developed on multiple platforms in response to a variety of consumer behaviors in terms of developing websites and applications (Website/Brand.com), electronic transaction (E-market place) and commerce through social media (Social Commerce/S-Commerce). In Thailand, the most common type of electronic commerce is S-Commerce having the highest influence on selling and buying by $40 \%$ [4]. However, it has been found that numerous sellers deal with obstacles in trading through many platforms. They have many patterns but do not know exactly how those patterns will meet their products including behaviors of consumers expected to be their target. Meanwhile, it is probably difficult to learn for some people who use social media for trading [5]. In addition, the researcher interviewed people involving SCommerce and found that S-Commerce required learning of techniques and selling methods by oneself until that person can figure out their own methods of conducting SCommerce that meets certain products or services.

Based on those articles, the researcher is aware of the importance of conducting S-Commerce in Thailand. Finding the most popular pattern of trading activities of conducting S-Commerce in Thailand through Facebook and LINE, since they are the top two social media and gain the most popularity for conducting S-Commerce in Thailand [6]. They can be guidelines for new business operators in selecting an 
appropriate pattern of conducting S-Commerce and a guideline for handling obstacles in conducting S-Commerce for existing business operators.

\section{LITERATURE REVIEW}

\subsection{Social Commerce}

Social Commerce or S-Commerce originated from the combination of two words; social media, online media provided for communication and e-commerce, selling and ordering products and services through networks over the internet [7]. When two words are combined, they give rise to a concept of community participation and social influence affecting online commerce [8].

S-Commerce is a communication strategy for promoting products or services or information to customers who are business targets. It requires three qualifications as $[4,7,9]$ :

1) Community interactions - various information is shared to increase confidence in products and services which may affect an increase in purchase order volume of products and services by consumers.

2) Social media technologies - are instruments available in social media which support trading activities such as customer ratings and reviews, social shopping tools, user recommendations and referrals, and forums and communities, etc.

3) Commercial activities including pre-sales, intermediate, and after-sales activities. Currently, trading activities through social media have not had explicit procedures and such activities shall be mentioned in the trading activity topic.

It can be said that S-Commerce can help businesses to achieve better customer service management by providing channels for customers to make enquiries and express their opinions, reviews of products and services including asking for help [10]. However, obstacles still exist in terms of no confidence in the process of buying products and services, especially methods of payment and unreliability of information posted on social media including wrong and improper information which all have a severe effect on the image and credibility of businesses [11].

\subsection{Facebook and LINE}

Since Facebook and LINE gain much popularity for conducting S-Commerce in Thailand [6], the researcher then studied functions in these two applications by giving importance to the main functions used for communicating but additional services are not included as shown in Table 1. 
Table 1. Communication functions of Facebook and LINE

\begin{tabular}{ll}
\hline \multicolumn{1}{c}{ Facebook [12,13] } & \multicolumn{1}{c}{ LINE [14,15] } \\
\hline - Find and add friends. & - Send a message and send a chat \\
- Find and follow companies, artists, & message to a person. \\
and other people. & - Send a message and send a chat \\
- Create a profile with one's information & message to a group. \\
such as employment history, & - Send various kinds of information \\
education background, religion, & such as messages, images, posters, \\
relationship status including favorite & and links to connect to external \\
songs and movies. & websites, applications, logos, video \\
- Create and share photo albums, event & clips, product lists, stickers, product \\
invitation and blog post. & logos, voice message, etc. \\
- Share videos and links to online & - Make a telephone call and video call \\
article, images, and others. & to people. \\
- Send an instant message and personal & - Increase a LINE official account for \\
message and post messages for a & organizations, businesses, and \\
public or friend only audience. & product brands to receive new \\
- Play online games and use other & information. \\
applications. & - Share information with messages, \\
- Privacy setting to control information & images, videos, and stickers or follow \\
shared with other people. & stories of persons through a \\
- "Check in" at places online by & timeline. \\
matching tag positions to update & - Save messages, images, and videos \\
status. & in LINE keep to save time finding \\
- Donate for charity, sign a petition & files and sharing things to people \\
online. & easily. \\
- Create a page fir companies, & - Broadcast real time live video in the \\
businesses, groups to publicize & chat room. \\
information for a public audience. & - LINE Square is a real-time community \\
- Find and join groups. & integrated with LINE's chat app, \\
- Broadcast live videos on Facebook. & allowing users to meet new people and \\
& share ideas of common interest. \\
\hline
\end{tabular}

\subsection{Buying and selling product activities}

Procedures of buying and selling products determined in this study are shown in Figure 1 by means of a body of knowledge about consumer decision-making process theory from Khan (2007) [16], Tyagi \& Kuma (2006) [17], Solomon (2010) [18] and the research conducted by DA COSTA TEVES (2013) [7] and Yadav, et al. (2013) [19]. In addition, the researcher conducted preliminary interviews with $10 \mathrm{~S}$-Commerce retail business operators to find the appropriateness of the real procedures through SCommerce based on the consumer decision-making process theory which found that there are important sub-activities in the purchase activity through S-Commerce is order, 
payment, and delivery. Therefore, the consumer decision-making process in this research should be broken down into six activities.

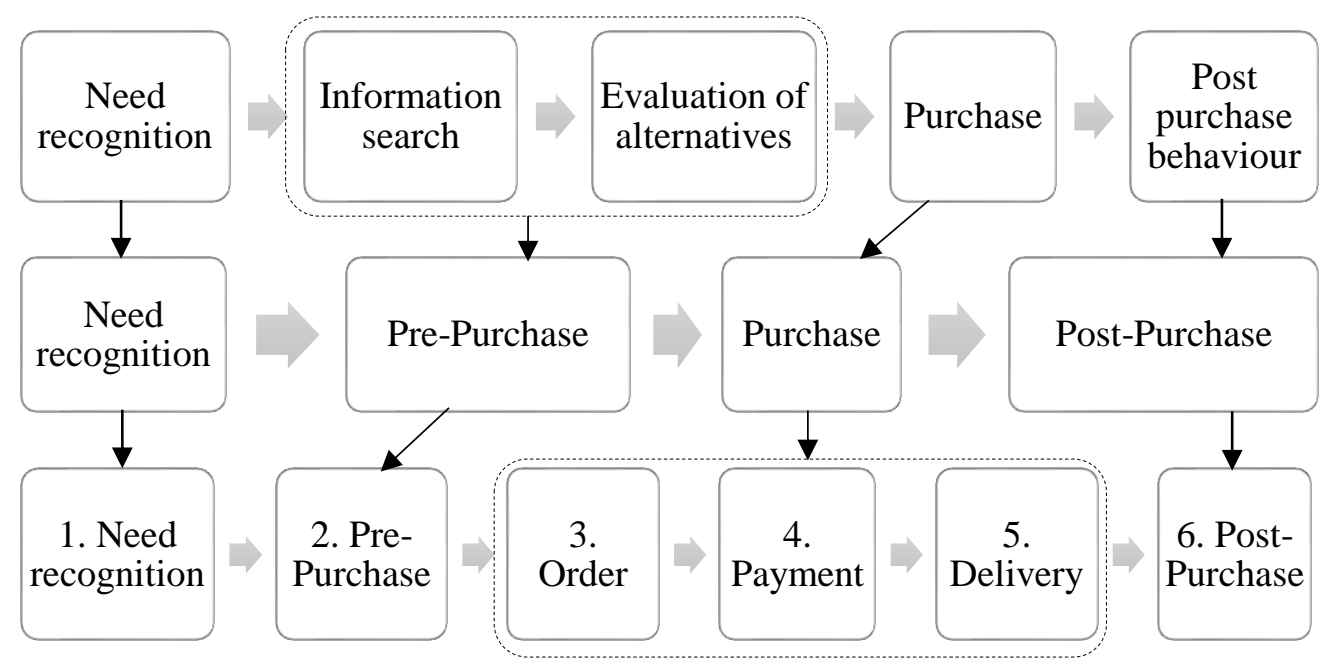

Figure 1. Consumer decision-making process to buying and selling activities

Figure 1 shows buying and selling activities consistent with the consumer decision-making process, which is divided into six major activities as follow:

1) Need recognition: It is an activity that promotes customers to be aware of problems and persuades customers to need to buy products. Information is given in many forms to target groups through proper channels.

2) Pre-purchase: Customers find information from many sources to compare worthiness for making a decision. Social media is a sources of product details, prices of delivery, payment channels, and other information identifying confidence in buying products and services.

3) Order: It is a process of ordering products by identifying names and details of products, places where products will be delivered. Buying products and services through social media most likely combines both online and offline processes.

4) Payment: Once customers make a purchase order, they shall make payment through a channel sellers specify. Buyers shall confirm the payment for sellers' acknowledgement through social media.

5) Delivery: When customers and sellers confirm the payment, sellers shall deliver products to customers through a specified channel. Information confirming the delivery shall be given to customers through social media. In this regard, online and offline processes are probably combined.

6) Post-purchase: When customers receive the products, they shall inform their satisfaction and dissatisfaction including suggestions and pass down information using word of mouth about buying and using the products with their friends or other people. A community is probably created for talking about the products or posting or sharing 
their feeling after buying, clicking the LIKE button or rating preference scores for those products and services.

\section{METHODOLOGY}

This study was conducted through the following steps:

3.1 Study functions and procedures of conducting S-Commerce on Facebook and LINE in accordance with buying and selling activities.

3.2 Investigate methods to carry out buying and selling activities through Facebook and LINE.

3.3 Analyze to figure out S-Commerce's operation activity patterns divided by methods of implementing buying and selling activities.

Overall details of the implementation can be shown in Figure 2. 


\section{1}

Study functions and procedures used to conduct S-Commerce on Facebook and LINE in accordance with buying and selling activities.

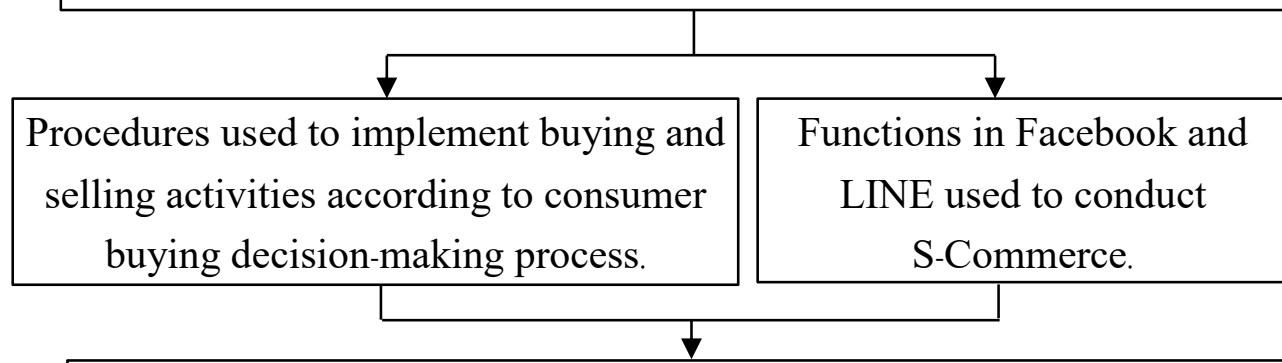

Procedures and functions used in each step to carry out buying and selling activities.

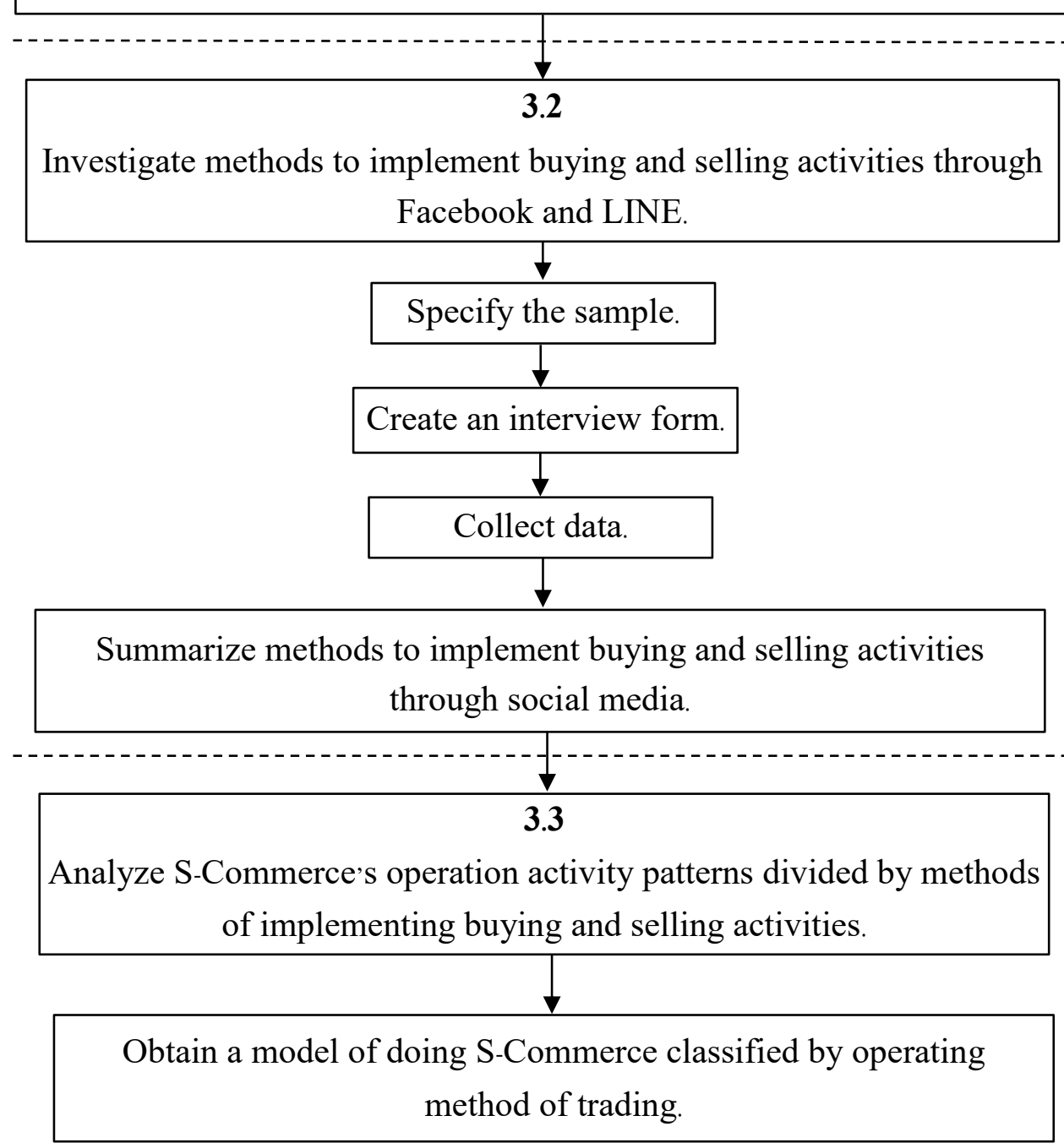

Figure 2. Diagram of procedures used to implement the research 


\subsection{Study functions and procedures used to conduct S- Commerce on Facebook and LINE in accordance with buying and selling activities}

Procedures of buying and selling activities in accordance with selected functions in Facebook and LINE are specified as shown in Table 2.

Table 2. Communication functions in Facebook and LINE in accordance with buying and selling activities

\begin{tabular}{|c|c|c|}
\hline $\begin{array}{c}\text { Buying and } \\
\text { selling activities }\end{array}$ & Facebook functions & LINE functions \\
\hline $\begin{array}{l}\text { 1. Need } \\
\text { recognition }\end{array}$ & $\begin{array}{l}\text { - Post messages, photos, } \\
\text { information for a public or } \\
\text { friend only audience. } \\
\text { - Log in to Facebook using } \\
\text { private/ group/ pages } \\
\text { accounts. } \\
\text { - Share videos/links to } \\
\text { related online articles. }\end{array}$ & $\begin{array}{l}\text { - Send messages, photos, posters, } \\
\text { and links to connect to external } \\
\text { sites and related video clips. } \\
\text { - Log in to LINE using } \\
\text { private/group account. } \\
\text { - Share related information on } \\
\text { timeline. }\end{array}$ \\
\hline 2. Pre-Purchase & $\begin{array}{l}\text { - Post details of products for } \\
\text { a public audience or } \\
\text { messages for friend only. } \\
\text { - Log in to Facebook using } \\
\text { private/group/pagesaccounts. } \\
\text { - Go live to broadcast details } \\
\text { of products. }\end{array}$ & $\begin{array}{l}\text { - Send details of products on } \\
\text { LINE chats. } \\
\text { - Log in to LINE using } \\
\text { private/group accounts. } \\
\text { - Share details of products on } \\
\text { timeline. } \\
\text { - Go live to broadcast product } \\
\text { details. }\end{array}$ \\
\hline 3. Order & $\begin{array}{l}\text { - Send purchase orders via } \\
\text { Messenger. } \\
\text { - Log in to Facebook using } \\
\text { private/group/pages. } \\
\text { - Post messages for a public } \\
\text { audience or for friend only. } \\
\text { - Go live to sell products in a } \\
\text { chat room. }\end{array}$ & $\begin{array}{l}\text { - Send purchase orders on } \\
\text { LINE chats. } \\
\text { - Log in to LINE using private/ } \\
\text { group accounts. } \\
\text { - Post purchase orders through } \\
\text { comment on timeline. } \\
\text { - Go live to sell products on a } \\
\text { chat room. }\end{array}$ \\
\hline 4. Payment & $\begin{array}{l}\text { - Confirm proof of payment } \\
\text { via Messenger. }\end{array}$ & $\begin{array}{l}\text { - Confirm proof of payment on } \\
\text { Messenger. }\end{array}$ \\
\hline 5. Delivery & $\begin{array}{l}\text { - Confirm product delivery } \\
\text { via Messenger. } \\
\text { - Login to Facebook using } \\
\text { private/group/pages } \\
\text { accounts. } \\
\text { - Post messages for a public } \\
\text { audience or in an inbox to } \\
\text { friends about product } \\
\text { delivery. }\end{array}$ & $\begin{array}{l}\text { - Confirm product delivery on } \\
\text { LINE chats. } \\
\text { - Log in to LINE using private/ } \\
\text { group accounts. } \\
\text { - Post messages through } \\
\text { comment on timeline. }\end{array}$ \\
\hline 6. Post-Purchase & $\begin{array}{l}\text { - Send messages and open a } \\
\text { private conversation on } \\
\text { Messenger. }\end{array}$ & $\begin{array}{l}\text { - Send product feedback on } \\
\text { LINE chats. } \\
\text { - Log in to LINE using private/ } \\
\text { group accounts. }\end{array}$ \\
\hline
\end{tabular}


Table 2. (Continued) Communication functions in Facebook and LINE in accordance with buying and selling activities

\begin{tabular}{clc}
\hline $\begin{array}{c}\text { Buying and } \\
\text { selling activities }\end{array}$ & \multicolumn{1}{c}{ Facebook functions } & \multicolumn{1}{c}{ LINE functions } \\
\hline & - Post messages for a public & audience or for friend only \\
& about ordered products. & timeline. \\
& - Login to Facebook using & \\
& private/group/pages & \\
& accounts. & \\
- Go live to review products. & \\
\hline
\end{tabular}

\subsection{Investigate methods to implement buying and selling activities through Facebook and LINE}

Based on functions in the Table 2, selection of Facebook and LINE functions in buying and selling activities were explored by interviewing 120 retail business operators. Convenience sampling technique was used to randomly select the sample in the Bangkok Metropolitan Region in which there are the highest number of people using social media in Thailand [20]. The retail business operators must conduct SCommerce no less than six months for showing their experience in doing S-Commerce, but should not exceed five years since by that time business operators used similar patterns of social media functions. The interviews took place during November 2019 to March 2020. The data obtained from the interviews was used to summarize methods to implement $\mathrm{S}$-Commerce buying and selling activities.

\subsection{Analyze S-Commerce's operation activity patterns divided by methods of implementing buying and selling activities}

The summary of methods to implement S-Commerce buying and selling activities from the interviews were analyzed to find out S-Commerce's operation activity patterns. In this study, there were three points used in the analysis:

- Methods used to implement buying and selling activities.

- Applications used in conducting S-Commerce.

- Functions used to implement buying and selling activities.

\section{FINDING}

Most of the sample used Facebook for S-Commerce, followed by using Facebook in combination with LINE, and LINE was least likely used for S-Commerce as shown in Table 3. 
Table 3. Number and percentage of retail businesses divided by applications used to conduct S-Commerce

\begin{tabular}{|c|c|c|}
\hline Applications & Number & Percentage \\
\hline Facebook & 71 & 59.17 \\
\hline Facebook and LINE & 29 & 24.16 \\
\hline LINE & 20 & 16.67 \\
\hline Total & 120 & 100.00 \\
\hline
\end{tabular}

The analysis of dimensional data according to the implementation of buying and selling activities ranging from need recognition, pre-purchase, order, payment, delivery to post-purchase indicated that S-Commerce had various patterns of buying and selling activities. Therefore, patterns of buying and selling activities from selected applications were considered as shown in Table 5 to Table 7. Letters were used to represent functions used to summarize the data as shown in Table 4.

Table 4. Letters representing functions in implementing buying and selling activities

\begin{tabular}{cl}
\hline Alphabet & \multicolumn{1}{c}{ Functions } \\
\hline F & $\begin{array}{l}\text { Post to a personal Facebook pages (need recognition only). } \\
\text { Post to a personal page and group page. }\end{array}$ \\
\hline FP & Post to business page (Facebook pages). \\
\hline FG & Post to group pages (Facebook group). \\
\hline FI & Chat in Facebook inbox. \\
\hline FLV & Broadcast on Facebook live. \\
\hline L & Chat on LINE chat. \\
\hline LG & Post to LINE timeline page. \\
\hline W & Give information and chat on LINE group chat. \\
\hline Tel & Give information through business websites. \\
\hline R & Have conversation over the telephone. \\
\hline
\end{tabular}

Table 5. S-Commerce's operation divided by methods used to implement buying and selling activities through Facebook

\begin{tabular}{lccccccc}
\hline Application & $\begin{array}{c}\text { Need } \\
\text { recognition }\end{array}$ & $\begin{array}{c}\text { Pre- } \\
\text { Purchase }\end{array}$ & Order & Payment & Delivery & $\begin{array}{c}\text { Post- } \\
\text { Purchase }\end{array}$ & $\%$ \\
\hline Facebook & FP & F/FI/Tel & FI & FI & FI & F & 14.08 \\
& F/FG & F/FI & FI & FI & FI & F/FI & 5.63 \\
& F/FP & F/FI & FI & FI & FI & F/FI & 4.22 \\
\hline
\end{tabular}

* The remainder of a variety of S-Commerce's operation activity patterns $=76.60 \%$

Table 5 shows that S-Commerce conducted through Facebook offered product information to serve need recognition through Facebook page since it is a channel many people can access and is reliable. Details of products were posted in pre-sales activities on Facebook pages. Customers were allowed to ask for more information about products through inbox and telephone. When customers would like to order products, 
they order through inbox and payment is informed/ confirmed through inbox. Inbox was also used to confirm product delivery. When customers received products, feedback from customers could be given through Facebook pages. This buying and selling activity pattern is the most likely to be found and accounted for $14.08 \%$ of SCommerce's operation activity patterns conducted through Facebook.

Table 6. S-Commerce's operation divided by methods used to implement buying and selling activities through Facebook in combination with LINE application

\begin{tabular}{lccccccc}
\hline Application & $\begin{array}{c}\text { Need } \\
\text { recognition }\end{array}$ & $\begin{array}{c}\text { Pre- } \\
\text { Purchase }\end{array}$ & Order & Payment & Delivery & $\begin{array}{c}\text { Post- } \\
\text { Purchase }\end{array}$ & $\%$ \\
\hline Facebook/ & $\mathrm{FP}$ & $\mathrm{F} / \mathrm{LT} / \mathrm{L} /$ & $\mathrm{L}$ & $\mathrm{L}$ & $\mathrm{R}$ & $\mathrm{F}$ & 10.34 \\
LINE & & $\mathrm{Tel}$ & & & & & \\
& $\mathrm{F} / \mathrm{L} / \mathrm{T}$ & $\mathrm{F} / \mathrm{LT} / \mathrm{FI} / \mathrm{L}$ & $\mathrm{FI} / \mathrm{L}$ & $\mathrm{FI} / \mathrm{L}$ & $\mathrm{FI} / \mathrm{L}$ & $\mathrm{F} / \mathrm{LT} / \mathrm{FI} / \mathrm{L}$ & 6.89 \\
& $\mathrm{FP} / \mathrm{LT}$ & $\begin{array}{c}\mathrm{F} / \mathrm{LT} / \mathrm{FI} / \\
\mathrm{L} / \mathrm{Tel}\end{array}$ & $\begin{array}{c}\mathrm{FI} / \mathrm{L} / \\
\mathrm{Tel}\end{array}$ & $\mathrm{FI} / \mathrm{L}$ & $\mathrm{FI} / \mathrm{L}$ & $\mathrm{F} / \mathrm{LT}$ & 6.89 \\
& & & & & \\
\hline
\end{tabular}

* The remainder of a variety of S-Commerce's operation activity patterns $=75.88 \%$

Table 6 shows S-Commerce conducted through Facebook in combination with LINE. Product information was given to serve need recognition through Facebook page to be accessible by a large number of people. Product details in pre-sales activities were given on Facebook page and LINE timeline. Customers were allowed to ask for more information about products through LINE chat and telephone. When customers would like to order products, inform and confirm payment, they did through LINE chat. Products were delivered directly to customers. When customers received products, feedback could be given through Facebook pages. This buying and selling activity pattern is widely found and accounted for $10.34 \%$ of S-Commerce's operation activity patterns conducted through Facebook in combination with LINE.

Table 7. S-Commerce's operation divided by methods used to implement buying and selling activities through LINE

\begin{tabular}{lccccccc}
\hline Application & $\begin{array}{c}\text { Need } \\
\text { recognition }\end{array}$ & $\begin{array}{c}\text { Pre- } \\
\text { Purchase }\end{array}$ & Order & Payment & Delivery & $\begin{array}{c}\text { Post- } \\
\text { Purchase }\end{array}$ & $\%$ \\
\hline LINE & $\mathrm{LT}$ & $\mathrm{LT} / \mathrm{L} / \mathrm{Tel}$ & $\mathrm{L} / \mathrm{Tel}$ & $\mathrm{L}$ & $\mathrm{L}$ & $\mathrm{LT} / \mathrm{L}$ & 35.00 \\
& $\mathrm{LT}$ & $\mathrm{LT} / \mathrm{L} / \mathrm{Tel}$ & $\mathrm{L} / \mathrm{Tel}$ & $\mathrm{L}$ & $\mathrm{L}$ & $\mathrm{L}$ & 10.00 \\
& $\mathrm{LT}$ & $\mathrm{LT} / \mathrm{L}$ & $\mathrm{L}$ & $\mathrm{L}$ & $\mathrm{L}$ & $\mathrm{LT}$ & 10.00 \\
\hline
\end{tabular}

* The remainder of a variety of S-Commerce's operation activity patterns $=45.00 \%$

Table 7 shows that S-Commerce conducted through LINE offered product information to serve need recognition through LINE timeline. Product details in presales activities were given on LINE timeline. Customers were allowed to ask for more information about products through LINE chat and telephone. When customers would like to order products, inform and confirm payment, they did through LINE chat. When customers received products, feedback could be given through LINE timeline and LINE chat. This buying and selling activity pattern is frequently found and accounted for $35.00 \%$ of S-Commerce's operation activity patterns conducted through LINE. 
The consideration of S-Commerce's operation activity patterns divided by the most common method used to implement buying and selling activities revealed that the implementation through Facebook accounted for $8.33 \%$ of all S-Commerce's operation activity patterns as shown in Table 8 . Product information was given to serve need recognition through Facebook pages. Details of products were posted in pre-sales activities through Facebook pages. Customers were allowed to contact for more information of products through inbox and telephone. Inbox was used for ordering products, informing/ confirming payment and confirming product delivery. Feedback from customers was given through Facebook page.

Table 8. S-Commerce's operation divided by the most common method used to implement buying and selling activities

\begin{tabular}{cccccccc}
\hline Application & $\begin{array}{c}\text { Need } \\
\text { recognition }\end{array}$ & $\begin{array}{c}\text { Pre- } \\
\text { Purchase }\end{array}$ & Order & Payment & Delivery & $\begin{array}{c}\text { Post- } \\
\text { Purchase }\end{array}$ & $\%$ \\
\hline Facebook & FP & F/FI/Tel & FI & FI & FI & F & 8.33 \\
\hline
\end{tabular}

Based on the consideration of selecting functions of applications in conducting SCommerce divided by buying and selling activities, regardless of the most frequently occurring patterns as shown in Figure 3, there was consistency with the most common S-Commerce's operation activity patterns. Table 8 shows the S-Commerce patterns that occurred are the ones that gained the most popularity in the Bangkok Metropolitan Region by the end of 2019 to the beginning of 2020as they were suitable for operators who did that business as their second jobs or had small capital for selling goods and goods can be changed easily.

\begin{tabular}{|c|c|c|c|c|c|c|c|c|c|}
\hline $\begin{array}{c}1 . \\
\text { Need }\end{array}$ & $\begin{array}{c}2 . \\
\text { Pre-Purchase }\end{array}$ & & $\begin{array}{c}3 . \\
\text { Order }\end{array}$ & & $\begin{array}{c}4 . \\
\text { Payment }\end{array}$ & & $\begin{array}{c}5 . \\
\text { Delivery }\end{array}$ & & $\begin{array}{c}6 . \\
\text { Post- }\end{array}$ \\
\hline recognition & Facebook & 1 & Inbox & 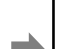 & Inbox & 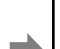 & Inbox & 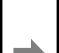 & Purchase \\
\hline Facebook & Pages and & & $(43.33 \%)$ & & $(45.83 \%)$ & & $(44.17 \%)$ & & Facebook \\
\hline Pages & Inbox & & & & & & & & Pages \\
\hline$(31.67 \%)$ & $(31.67 \%)$ & & & & & & & & $(39.17 \%)$ \\
\hline
\end{tabular}

Figure 3. Used functions divided by buying and selling activities

The researcher asked for opinions from S-Commerce sellers and buyers and found that buyers most likely viewed products through Facebook since they regularly use it. They can better find, retrieve, display products and product details from Facebook than other applications. They enjoy seeing product reviews and see a number of followers to gain trust and rate reliability. Purchase orders can be done through inbox which allows more information to be asked. Some of them found that sellers gave late response and did not answer what was being asked in the inbox. Now, a combination of instruments is seen being used more and more, Facebook is suitable for promotion of goods and giving information to a large number of target groups, but for buying 
activities LINE is selected for talking and asking for more details from sellers. LINE is used for closing a deal as it gives more privacy.

Sellers viewed that an increase in trading channels will enable them to reach more customers but they need to have preparedness in sales management. A number of system administrators should be increased as well as availability of a better inventory management system, which actually requires additional expenses and is suitable for sellers with a large amount of capital. For sellers with small capital, they try to specify a single channel for product ordering but present their products on other channels to which customers have better access; for example, presenting their products on Facebook and Instagram but customers can order products through LINE only so as to reduce a channel for managing purchase orders. Some groups of buyers viewed that it was inconvenient if they can buy from a single channel only.

\section{DISCUSSION}

S-Commerce has gained much popularity in Thailand and has become a channel for running a trading business for independent sellers who have small capital. In this regard, they start a marketing strategy in creating a brand through social media by seeking benefits from the preferences of Thai people who spend most of their time on social media [21]. It has been found that $62 \%$ of people most likely buy products through S-Commerce and during the COVID-19 situation, $83 \%$ of people preferred to buy online since they needed to adjust their behaviors due to social distancing to avoid the spread of the disease. Since they had to spend their money in daily life, they increasingly turned to buy products through S-Commerce. This is suitable for Thai people's behaviors as they like to talk, question, and build relationships between sellers and buyers, though they do not see each other face to face [22]. Meanwhile, the delivery business has been expanding, supporting S-Commerce to rapidly grow under the COVID-19 situation and in the future. This research views the importance of finding S-Commerce's operation activity patterns so as to be a guideline for implementing buying and selling activities in Thailand. The study results indicated that the implementation occurred on Facebook the most since it is one of the most popular applications that can be used being the number one channel for conducting SCommerce, especially Facebook pages that can build increasing reliability to sellers. Later, people use LINE for communication more and more. To build confidence and privacy in talking, S-Commerce business operators have carried out trading activities by using Facebook in combination with LINE [23] so as to add more channels for buying and selling goods in which good management of purchase orders and inventory is required. Goods are presented through several channels but channels for placing orders are controlled to ensure efficient purchase order management, which is suitable for small S-Commerce business operators with small capital.

Recently, additional applications have been developed to connect to Facebook Messenger (for Facebook pages) and LINE OA for making contact with customers 
conveniently in terms of ordering, checking product status, and checking information. Moreover, frequently asked questions can be configured. However, some limitations are found in terms of adaptation, connection of functions to applications, and increasing expenses. Therefore, if social media application service providers can develop those functions by themselves and allow sellers to use them without complicated configurations that they do not have to pay for or are able to pay minimal expenses, it can reduce the weakness of S-Commerce's operation activity patterns with regard to purchase order management and information confirmed by more than one channel. This will make S-Commerce business operators gain more success and stimulating the country's economy.

Besides, S-Commerce in Thailand has some limitations in terms of expanding business to customers in foreign countries due to differences in language and communication [24] including requirements or laws related to international trading. The buying and selling of goods on social media has increased across the world by $34 \%$ and the use of social media is expected to increase continuously. Facebook is still popular among people worldwide to find and order products. Thailand has many types of goods that are interesting such as pictures, ornaments, watches, clothes, etc. [25]. Consequently, if applications used to conduct S-Commerce are developed to have an automatic translation system starting from posting details of goods and discussions for ordering of goods including a system to find suitability of goods to be sold for foreign customers, it is very important to be informed on International trading laws as well as those for specific countries, S-Commerce can be expanded to foreign customers.

In addition, the concepts and methods of conducting this research can be a model of research methodology for similar research in other countries in order to find the most popular pattern of trading activities through S-Commerce in each country.

\section{LIMITATION}

This research was conducted to find out S-Commerce's operation activity patterns divided by methods used to implement buying and selling activities through Facebook and LINE only since Facebook and LINE are applications popular among Thai people. Emphasis was placed on the implementation of buying and selling though the main functions supporting communication on social media only.

\section{FURTHER RESEARCH}

1) Data should be additionally collected from the implementation of S-Commerce divided by types of goods and an interview should be made with sellers who gain success from conducting S-Commerce of various kinds of goods. Analysis of additional details of each type of goods should be made to gain more patterns of conducting SCommerce. 
2) In order to facilitate a tendency of S-Commerce expansion to foreign customers, a study on behaviors in ordering goods through S-Commerce of foreigners should be conducted. International level S-Commerce's operation activity patterns should be analyzed. Laws related to international trading of each country should be studied to be brought as a guideline for developing a system to seek suitability and legality of goods sold and bought through S-Commerce.

\section{REFERENCES}

[1] A. Aroonpiboon. (2015, February, 26). "Digital Economy Policy," [Online]. Available: http://www.thailibrary.in.th/2015/03/15/digitaleconomy

[2] M. Išoraitè and N. Miniotienè, "Electronic commerce: Theory and practice," Integrated Journal of Business and Economics, Vol.2, No.2, pp. 73-79, 2018.

[3] Kasikorn Research Center, "Adjust business to catch up with the growing ecommerce trend,” Bangkok: KASIKORN Research Center Company Limited, 2017.

[4] G. Sachs, A. Statista, W. Frost \& P. Sullivan, "E-Commerce Survey,” ETDA, 2018.

[5] P. Pongvitayapanu, "Thailand Social Commerce," Thailand ZOCIAL Awards, 2017.

[6] Bsullivan. (2019, October, 13). "Thailand Business News - Retail in the age of social media - Ecommerce, Facebook, Real Estate, Social Media, Tec,". Siam News Network. [Online]. Available: https://www.siamnews.biz13957-thailandbusiness-news-retail-in-the-age-of-social-media-ecommerce-facebook-realestate-social-media-tech.

[7] T. DA COSTA TEVES, "Social commerce: conceptual model and customer perception, " master graduation thesis, science in management engineering. Italy: politecnico Milano, 2013.

[8] H. Han \& S. Trimi, "Social commerce design: A framework and application," Journal of theoretical and applied electronic commerce research. Vol.12, No.3, pp. 50-68, 2017.

[9] E. Turban, J. Outland, D. King, J.K. Lee, T.P. Liang \& D.C. Turban, "Electronic commerce 2018: A managerial and social networks perspective," Springer, 2017.

[10] T.R. Wagner \& J. Hughes, "Social CRM: the new frontier of marketing, sales and service," Dublin: Accenture, 2010.

[11] S. Spencer, J. Harding \& J. Sheahan, "Social ecommerce: Increasing sales and extending brand reach,” Massachusetts: O'Reilly Media, Inc., 2014.

[12] Queens Library, "Facebook tutorial: An introduction to today's most popular online community,” New York: Queens Public Library, 2019.

[13] Facebook (2019, April, 29). “Using Facebook. Facebook Help Centre," [Online]. Available: https://www.facebook.com/help/?helpref=hc_global_nav.

[14] S. Kuljitjuerwong, "LINE-Communicating format on the creativity of Smartphone: Benefits and limits of application,” Executive Journal. Vol.33, 
No.4, pp. 42-54, 2013.

[15] LINE Corporation (2019, April, 29). “LINE Information,” [Online]. Available: https://line.me/en/

[16] M. Khan, "Consumer behaviour," New Age International, 2007.

[17] C.L. Tyagi \& A. Kumar, "Consumer behaviour," Atlantic Publishers \& Dist, 2004.

[18] P. Ruangsakul. (2020, November, 20). "E-Commerce 2020-2021, How to Sell?(Part 2)," [Online], Available: https://medium.com/incart/e-commerce2020-2021-2-fb-ig-website-line-127c3a3003c7.

[19] M.S. Yadav, K. De Valck, T. Hennig-Thurau, D.L. Hoffman \& M. Spann, "Social commerce: A contingency framework for assessing marketing potential, ”Journal of interactive marketing. Vol.27, No.4, pp. 311-323, 2013.

[20] WP (2018, February, 27). "Worldwide digital user statistics Thailand is the most addictive internet in World-Bangkok, the city with the highest Facebook users," [Online]. Available: https://www.brandbuffet.in.th/2018/02/global-and-thailanddigital-report-2018/.

[21] P. Booasang. (2017, October, 13). "Social Commerce, the online trading trend that is as strong as Lazada," [Online]. Available: https://brandinside.asia/socialcommerce-eic research/.

[22] Pigabyte. (2020, October, 13). "The horror of social commerce at the online marketplace must be careful," [Online]. Available: https://www.marketing oops.com/news/ biz-news/social-commerce-3/.

[23] M.R. Solomon, “Consumer behaviour: A European perspective," Pearson education, 2010.

[24] Jarukornsaku, J. (2020, November, 20). "Social Commerce,” WHA Group. [Online]. Available: https://www.wha-group.com/en/news-media/companynews /401/social-commerce.

[25] M. Djordjevic. (2020, November, 20). "32 Stunning Social Commerce Statistics for 2020," SaveMyCent. [Online]. Available: https://savemycent.comsocialcommerce-statistics/. 